\title{
A Generic Feature Extraction Approach for Dealing with Multiple Attribute Decision Analysis Problems under Risk and Uncertainty
}

\author{
Md. Zahid Hasan \\ Department of Computer Science and Engineering \\ Jahangirnagar University \\ Dhaka, Bangladesh \\ zahid.cse@diu.edu.bd \\ Mohammad Shorif Uddin \\ Department of Computer Science and Engineering \\ Jahangirnagar University \\ Dhaka, Bangladesh \\ shorifuddin@gmail.com
}

\author{
Shakhawat Hossain \\ Department of Computer Science and Engineering \\ International Islamic University Chittagong \\ Chattogram, Bangladesh \\ shakhawat.cse@outlook.com \\ Mohammad Shahidul Islam \\ Institute of Information Technology \\ Jahangirnagar University \\ Dhaka, Bangladesh \\ suva93@gmail.com
}

\begin{abstract}
This paper represents a generic feature extraction approach to handle multiple attribute decision analysis problems. For that purpose, available decision support frameworks are carefully studied and the basic types of attributes involved in the decision problems are identified. Based on this analysis, a generic decision support scheme is proposed that can deal with all sorts of attributes in order to deduce the optimal solution for any decision problem. The proposed framework is capable of handling multiple attributes throughout the process of providing a flawless solution for the decision problem under both risk and uncertainty. This paper provides detailed information about the sources of uncertainty in the decision-making process and proposes a sophisticated approach for capturing all sorts of uncertainties. In the proposed approach, a cross assessment of every attribute against the corresponding attribute of the other alternatives is conducted to extract the significant features of an attribute. The relative importance of every attribute is considered as a supporting knowledge representation parameter in order to optimize the attribute-assessment process. The final decision is made based on the numerical scores seized by the alternatives. The paper also represents a numerical study to demonstrate the potential applications of the proposed methodology.
\end{abstract}

Keywords-multi-attribute; decision problem; feature extraction; knowledge base; uncertainty; risk; cross evaluation

\section{INTRODUCTION}

Dealing with multiple attributes for making the right decision is a key challenge for a business or an organization. Both businesses and organizations need to analyze a huge number of data for solving decision problems during planning and operation. In the real world, a different type of attributes may need to be considered for making the right decision [1-6]. So, there is an extended demand for decision support frameworks for handling multiple attribute decision analysis problems [7-10]. Though numerical attributes are comparatively easier to calculate during decision making, qualitative attributes require a different evaluation process. On the other hand, mapping Boolean data with qualitative or quantitative data is not always easy. Besides, existing frameworks can make decisions fall into either under uncertainty or at a risk which leads a decision maker to implement two separate decision support systems. Moreover, considering all the attributes with equal importance may lead to an inappropriate decision. So, it is important to allocate weights to the decision attributes in order to find the best possible solution for a decision problem. Unfortunately, there is no suitable decision framework that can evaluate qualitative, quantitative and Boolean data with respect to their weights for finding the ultimate alternative for supporting a decision.

It is significant for decision makers to comprehend the idea of uncertainty so as to improve their competence to take decisions and to make a balance of risk related to their decisions. In addition, their comprehension of the idea of uncertainty could bring down inconsistency rates and give an increasingly powerful and respectable illustration of the impact of uncertainty on the performance of a decision making model. In real-life decision-making problems, most people are just able to deal with a few attributes at the same time [11], but they can hardly handle multiple attributes in an effective way to find out a reasonable ultimate outcome. To solve the decision problem under uncertainty, the Bayes-Minimax algorithm was proposed as a decision support framework for the first time in 1951 [12]. Unfortunately, this decision support framework could only handle a single attribute decision problem which raised an extended demand for a robust decision framework that would be capable of solving multi-attribute decision problems. In 1954, authors in [13] proposed the Simple Additive Weighting Method (SAWM) for dealing with 
Multiple Attribute Decision Analysis (MADA) problems [13] which could calculate the impact of a set of actions for a certain operation along with its importance for optimizing the decision-making process. In 1980, an Analytical Hierarchy Process (AHP) was proposed [14-15] for handling different MADA problems in various fields of engineering and management. It was stated that if the ratio of inconsistency is greater than $10 \%$, the performance of decision-making process can be degraded [16]. AHP addresses complex decisions by making a pair wise comparison among the decision criteria. In addition, it captures both subjective and objective attributes of a decision problem. Authors in [2] suggested the Technique for Order of Preference by Similarity to Ideal Solution (TOPSIS) as the most suitable model for capturing multiple attributes in order to choose the most feasible alternative [14, 15, 17, 18]. Although the TOPSIS method provides an optimal solution for MADA problem, many decision experts oppose using TOPSIS because of its time complexity. On the other hand, a grey-based decision-making approach was used in [19] for the supplier selection problem. In the grey-based approach, the weights and attributes of all the alternatives are first defined by some linguistic variables and then some grey possibility degrees are used to rank the order of all the alternatives. At the same time, some researchers proposed the Fuzzy Set theory to solve multiple attribute decision problems [20-25] under uncertainty. Some researchers suggested the Dempster-Shafer (D-S) theory [26] instead of using the traditional probability theory to improve the process of capturing uncertainty while developing the decision support systems.

Recently, the Evidential Reasoning (ER) approach was proposed [27-28] for solving different decision problems. ER approach is able of handling both qualitative and quantitative attributes to order the rank of a group of alternatives. Authors in $[6,28,29]$ used the Evidential Reasoning (ER) approach for solving multiple attribute assessment problems. Finally, Rulebased Inference Methodology using Evidential Reasoning (RIMER) [30] was proposed in 2006. The RIMER approach is a hybrid mathematical framework, constructed with the combination of Bayesian probability theory, Dempster-Shafer (D-S) theory of evidence, and fuzzy set theory for demonstrating and reasoning with uncertain knowledge. Though many researchers appreciate RIMER approach for solving decision problems under uncertainty, some find it complex and not a flawless process for capturing uncertainty. At the same time, some researchers concentrated on establishing decision support frameworks under risk. Risk can be defined as uncertainties which can emerge a positive or negative impact on the solution of a decision problem. Finding the optimal solution for a decision problem without the proper management of its risk is almost impossible. Therefore, decision scientists have been trying to establish a suitable methodology in order to manage the risks involved in multiattribute decision analysis problems. For the first time, in 1944, Von Neumann \& Morgenstern proposed Expected Utility Theory (EUT) for solving decision-making problems under risk [31]. But, Allais had a doubt about the accuracy of the Expected Utility Theory and he mentioned how EUT is unable to capture human problems [32]. To solve Allais paradoxes and enhance decision support frameworks, a number of decision theories were proposed. Authors in [33] proposed the prospect theory for helping people make the optimal decision by evaluating some potential values rather than depending on the final outcome. Later in 1992, cumulative prospect theory was proposed as the improved version of the prospect theory, for handling both risky and uncertain information in order to acquire the optimal decision solution [34]. In 1974, the Configural Weight Models [35] were suggested for solving decision problems with risky prospects. The authors implemented the transfer of attention exchange (TAX) model to predict results from some previously estimated data [36]. In 2001, authors in [37] proposed Minimax algorithm to solve decision problems under risk [37]. Recently, the author in [38] developed the opportunity-threat theory for dealing with the new paradoxes in cumulative prospect theory which benefits the decision makers in selecting the optimal alternative. Unfortunately, the opportunity-threat theory is not capable of analyzing all type of data for making the optimal decision for a certain type of MADA problems.

Based on the above analysis, it becomes clear that some researchers focused on decision making under uncertainty while others concentrated on decision making under risk. So, there should be a decision framework able to provide an optimal solution for a decision problem under both risk and uncertainty. This paper proposes a new generic decision framework to handle all types of data for choosing the optimal alternative under both uncertainty and risk. The proposed framework is less complex and capable of handling all sorts of uncertainty and risks throughout the decision-making process.

\section{FEATURE EXTRACTION APPROACH FOR MULTIPLE ATTRIBUTE DECISION PROBLEMS}

\section{A. Decision Attribute}

There are basically three types of attributes in a decision support system.

\section{1) Qualitative}

Qualitative attributes are subjectively judgmental. For example, the performance of a computer can be evaluated as Average, Good or Excellent. In the Feature Extraction Approach, these subjective inputs are transformed into some numerical values. The domain experts set the numerical values against the subjective evaluation. For instance Average can be transformed into 0.1 , Good can be transformed into 0.5 and Excellent can be transformed into 1 . The size and numerical evaluation of the subjective grades of an attribute can vary depending on experts' opinions.

\section{2) Quantitative}

Quantitative attributes describe numerical values. For example, the price of a computer is $\$ 100$.

\section{3) Boolean}

The input for a Boolean attribute can be either true or false. The proposed Feature Extraction Approach considers ' 1 ' and ' 0 ' to address the 'true' and 'false' statements. 


\section{B. Additional Knowledge Representation Parameter: Attribute Weight}

Attribute weight states the relative importance of an attribute and is numerically described to address the impact of an attribute on the decision making process. A precise decisionmaking process mostly depends on its attributes' weights. For example, suppose a school committee declares to appoint a math teacher. To select the best alternative, the committee sets two parameters as the basic quality measurement attributes: Math Score and Music Performance Score.

\section{Results for two alternatives are}

$$
\begin{aligned}
& C_{1}=\text { (Math, 0.6) and (Music, 0.3) } \\
& C_{2}=\text { (Math, 0.4) and (Music, 0.6) }
\end{aligned}
$$

Now, if both attributes are considered with equal importance, then $C_{2}$ will be selected, though $C_{1}$ scored higher in math test and should actually be selected. On the other hand, if the committee wanted to appoint a music teacher from these two alternatives then $C_{2}$ would have been selected. So, it is necessary to set some importance for each attribute based on a certain decision-making aspect. Attribute weights can be set by domain experts or by analyzing historical data. Geometric mean method [39], geometric least squares method [39], and eigenvector method [40] provide very well-formed formulas to extract attribute weights from historical data.

\section{Basics about Decision Making Framework}

\section{1) Representation Schema}

Feature extraction approach analyzes the attributes of all the provided alternatives to choose the best alternative for a possible operation. Suppose there are $N$ distinct alternatives $C_{i}(i=1, \ldots \ldots, N)$ for a particular operation. So, the alternatives can be represented as:

$$
C=\left\{C_{1}, C_{2}, \ldots, C_{i}, \ldots, C_{N}\right\}
$$

Suppose, there are $L$ basic attributes $e_{j} \quad(j=1, \ldots ., L)$ associated with every alternative. The basic attributes can be stated as follows:

$$
E=\left\{e_{1}, e_{2}, \ldots, e_{j}, \ldots, e_{L}\right\}
$$

So, the basic attributes for $e_{j}(j=1, \ldots \ldots, L)$ of an alternative can be mathematically represented as $e_{i, j}$; where, $i(i=1, \ldots, N)$ is the number of alternatives and $j(j=1, \ldots, L)$ is the number of attributes. $e_{i, i}$ denotes the $j^{\text {th }}$ attribute $\left(e_{j}\right)$ of the $i^{\text {th }}$ alternative $\left(C_{i}\right)$. For example, $e_{1,2}$ means the $2^{\text {nd }}$ attribute of the $1^{\text {st }}$ alternative where $e_{2,1}$ means the $1^{\text {st }}$ attribute of the $2^{\text {nd }}$ alternative. Again, the attributes of an alternative can be represented using some belief degrees against a predefined evaluation grade.

\section{2) Attribute Expression Matrix}

The basic attributes of each alternative can be presented using an attribute expression matrix. The attribute expression matrix provides a transparent visualization of the attributes' input against their respective alternatives. In the case of qualitative attributes, the attribute expression matrix exhibits the attributes evaluation grade along with its belief degree. For example, the input for attribute $a_{11}$ can be presented as (good, 0.5 ) meaning the user is $50 \%$ sure that the input for attribute $a_{11}$ will be good. Suppose, $H=\left\{H_{1}, H_{2}, \ldots \ldots, H_{m}\right\}$ is a set of evaluation grades to which all the qualitative attributes for a decision support problem are measured. The degree of belief against the evaluation grade can be presented using some numerical values, $B_{n}(n \in R)$. The basic attributes expression matrix can be structured as shown in Table I.

\section{TABLE I. ATTRIBUTE EXPRESSION MATRIX}

\begin{tabular}{|c|r|r|r|r|c|}
\hline \multirow{2}{*}{ Alternative } & \multicolumn{5}{|c|}{ Attribute } \\
\cline { 2 - 6 } & $\mathrm{a}_{1}$ & $\mathrm{a}_{2}$ & $\mathrm{a}_{3}$ & $\ldots$ & $\mathrm{a}_{\mathrm{m}}$ \\
\hline $\mathrm{A}_{1}$ & $\mathrm{a}_{11}$ & $\mathrm{a}_{12}$ & $\mathrm{a}_{13}$ & $\ldots$ & $\mathrm{a}_{1 \mathrm{~m}}$ \\
\hline $\mathrm{A}_{2}$ & $\mathrm{a}_{21}$ & $\mathrm{a}_{22}$ & $\mathrm{a}_{23}$ & $\ldots$ & $\mathrm{a}_{2 \mathrm{~m}}$ \\
\hline $\mathrm{A}_{3}$ & $\mathrm{a}_{31}$ & $\mathrm{a}_{32}$ & $\mathrm{a}_{33}$ & $\ldots$ & $\mathrm{a}_{3 \mathrm{~m}}$ \\
\hline$\vdots$ & $\vdots$ & $\vdots$ & $\vdots$ & $\vdots$ & $\vdots$ \\
\hline $\mathrm{A}_{\mathrm{n}}$ & $\mathrm{a}_{\mathrm{n} 1}$ & $\mathrm{a}_{\mathrm{n} 2}$ & $\ldots$ & $\ldots$ & $\mathrm{a}_{\mathrm{nm}}$ \\
\hline
\end{tabular}

In Table I, $A_{n}\{n(n \in R)\}$ is the number of alternatives, and $a_{n m}\{m(m \in R)\}$ is the number of attributes representing the input of an alternative. If the input variables are qualitative, the representation of the input variables will hold its evaluation grade along with its belief degrees. In that case, $a_{n m}$ will be represented as $\left(H_{n m}, B_{n m}\right)$. On the contrary, $a_{n m}$ will be replaced with a numerical value if the input type is quantitative. In case of Boolean data, $a_{n m}$ will accept only a binary statement: yes or no.

\section{3) Handling Uncertainty due to Incomplete Information}

One of the most important tasks for a decision support framework is to handle uncertainty during processing of the information of a decision problem. Uncertainty may come from human ignorance in case of providing inputs or from the vulnerability of the utilized model. Though it is expected that the input provider will provide complete data for each input in most of the cases the input provider fails to provide complete information. In that case, the system needs to infer the final result using some incomplete data. For instance, the input for the attribute, 'quality of a teacher' can be achieved as, (Good, 0.8 ) which means, the input provider is $80 \%$ sure that the quality of the teacher is Good. So, the remaining $20 \%$ is ignorance in this case. Or, the input provider may fail to provide any information about the quality of the teacher. Thus, information may come with partial or full ignorance. In case of full ignorance, obtained uncertainty can be handled with the help of a knowledge base. In the proposed methodology, knowledge base is constructed using some if-then rules. These if-then rules are set by a group of domain experts. The basic rules can be represented as follows:

$$
\begin{gathered}
R_{K}^{L}: \text { if }\left\{\left(A_{1}, B_{1}\right) \wedge\left(A_{2}, B_{2}\right) \wedge \ldots \ldots \wedge\left(A_{n}, B_{T}\right)\right\} \\
\quad \text { then }\left\{\left(D_{1}, \bar{B}_{1}\right),\left(D_{2}, \bar{B}_{2}\right), \ldots,\left(D_{n}, \bar{B}_{n}\right)\right\}
\end{gathered}
$$

where $R_{K}^{L},\{(K=(1,2, \ldots, N)$ is the number of rules and $L=(1,2, \ldots, N)$ represents the number of attributes $\}$ represents the rule for the knowledge base. $A_{i}=\left\{A_{1}, A_{2}, \ldots, A_{T}\right\}$ represents attributes' evaluation grade and $B_{i}\{i \in(1, \ldots, N)\}$ is the degree of belief in terms of $A_{i} . D_{i}(i=1,2, \ldots, N)$ is the rule consequence and $\bar{B}_{i k}\{(i=1,2, \ldots, N),(k=1,2, \ldots, N)\}$ is the degree of belief in terms of $D_{k}$. Here, $\sum B_{i k} \leq 1$ and $\sum \overline{B_{l k}} \leq 1$. 
The degree of belief $B_{i k}$ can be represented by a fuzzy membership function. In that case, (3) can be written as:

$$
\begin{gathered}
R_{K}^{L}: \text { if }\left\{\begin{array}{c}
\left(A_{1}^{k}, B_{1 k n} \text { to } B_{1 k m}\right) \wedge\left(A_{2}^{k}, B_{2 k n} \text { to } B_{2 k m}\right) \\
\wedge \ldots \ldots \wedge\left(A_{T}^{k}, B_{T k n} \text { to } B_{T k m}\right)
\end{array}\right\} \\
\text { then }\left\{\left(D_{1}, \bar{B}_{1 k}\right),\left(D_{2}, \bar{B}_{2 k}\right), \ldots,\left(D_{n}, \bar{B}_{n k}\right)\right\}
\end{gathered}
$$

where $n$ represents the minimum degree of belief in fuzzy membership function and $m$ presents the maximum degree of belief in fuzzy scale, and $\sum\left(B_{i k n}+B_{i k m}\right) \leq 1$. For example:

$R_{1}^{1}:$ if $\{($ Good, $(0.2-0.4)\} \wedge\{($ Fair $(0.3-0.6)\}$ then $\{($ Good, 0.2$)$, (average, 0.3$)($ Fair, 0.5$)\}$

The final input for attribute $a_{i j}$ can be measured as:

$$
a_{i j}=\sum_{i=0}^{i=1} A_{i} B_{i}
$$

\section{4) Decision Modeling with Non-obtainable Data}

A decision problem becomes more complex when the user fails to provide any information about an attribute for an alternative. Due to this type of ignorance, decision frameworks often fail to provide an optimal solution for a decision problem. This paper proposes a breakdown approach to process this type of non-obtainable information. For example, to decide whether an applicant is valid for a house loan or not, a bank needs to check the following criteria: credit score, affordability, property evaluation, monthly income, and expenses declaration. Suppose the bank manages the necessary information about all the above attributes apart from the 'property evaluation'. So, the input for the attribute 'property evaluation' is non-obtainable for the bank. To process this type of non-obtainable information, the attribute needs to be broken down into its sub-attributes. For instance, the property evaluation can be assessed by the following sub-attributes:

- Does the candidate own a house?

- Does the candidate own a car?

- Is the candidate in possession of land or property?

- Does the candidate have a private business?

Thus the total ignorance of an attribute can be completely handled by providing information about all of its sub-attributes. If the user fails to provide sufficient information about any of these sub-attributes, then the attribute information will be partially incomplete and can be handled by the process stated in Section III.

\section{5) Attribute Analysis and Feature Extraction}

Feature Extraction Approach (FEA) analyzes the attributes of all the provided alternatives to choose the best alternative for a possible operation. To analyze the attributes precisely, FEA makes a cross evaluation among the respective attributes of every given alternative. For that, FEA finds the minimum value of a particular attribute from every alternative. The minimum value of the attribute $j$ for the given alternatives is called floor value and can be expressed as:

$$
\alpha_{j}=\min \left(e_{i, j}\right)
$$

where $i$ is the number of alternatives, $j$ is the number of attributes and $\alpha_{j}$ is the minimum value of the $j^{\text {th }}$ attribute. For example, for the $1^{\text {st }}$ iteration, $\alpha_{1}(j=1)$ expresses the minimum value of the $1^{\text {st }}$ attribute of all the alternatives. And for the $2^{\text {nd }}$ iteration, $\alpha_{2}(j=2)$ expresses the minimum value of the $2^{\text {nd }}$ attribute of all the alternatives.

Feature extraction is the easiest way to demonstrate the extent a certain attribute of an alternative differs from the same attribute of the other alternatives. The basic feature extraction is done by calculating the arithmetic difference between the minimum value of a certain attribute and the same attribute of all the alternatives:

$$
\beta_{i, j}=e_{i, j}-\alpha_{j}
$$

where $\beta_{i, j}$ determines the feature of the $j^{\text {th }}$ attribute of the $i^{\text {th }}$ alternative with respect to the $j^{\text {th }}$ minimum value $\left(\alpha_{j}\right)$.

\section{6) Decision Making using Feature Extraction Approach}

Suppose, the attributes' weights are represented as $w_{j}$; where $j(j=1, \ldots, L)$ is the number of attributes. $w_{j}$ states the weight of the $j^{\text {th }}$ attribute $\left(e_{j}\right)$ with $0<w_{j} \leq 1$. The weight of an attribute is always greater than 0 because if the weight of an attribute is considered to be 0 the attribute becomes useless for that operation. Let $m_{i, j}$ be the basic probability mass for the $j^{\text {th }}$ attribute of the $i^{\text {th }}$ alternative. The probability mass of an attribute can be calculated by:

$$
m_{i, j}=\prod_{i=1, j=1}^{i=N, j=L}\left(\beta_{i, j}, w_{j}\right)
$$

where $w_{j}$ is the relative importance of the $j^{\text {th }}$ attribute.

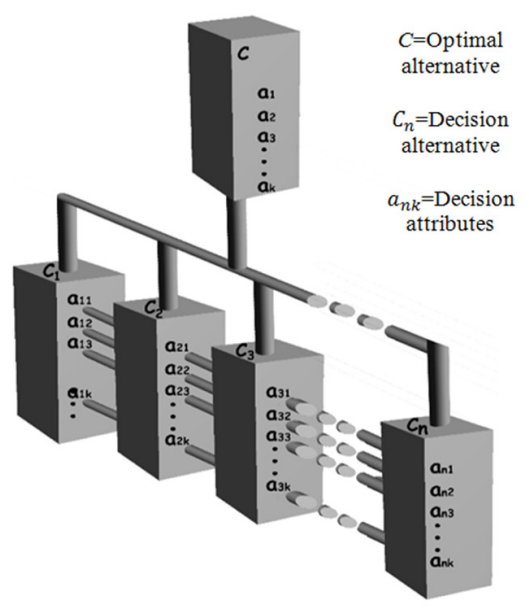

Fig. 1. Feature extraction model

Finally, the utility or risk-severity of an alternative is calculated by aggregating its probability masses. The basic arithmetic summation formula is used to aggregate the probability masses:

$$
C_{i}=\sum_{i=0, j=0}^{i=N, j=L} m_{i, j}
$$

where, $C_{i}(i=0, \ldots, N)$ is the utility of $i^{\text {th }}$ alternative.

To make the final decision or choose the best alternative for a certain operation, the utilities scored by the alternatives are 
analyzed. And then, based on the operation nature, the final decision is made. So, the best alternative can be chosen as:

$$
C=\left\{\begin{array}{l}
\max \left(C_{i}\right) \text { for benefit attributes } \\
\min \left(C_{i}\right) \text { for cost attributes }
\end{array}\right.
$$

Here, $i(i=1,2, \ldots \ldots, N)$ is the number of alternatives. The feature extraction model is shown in Figure 1. The value for $C$ in (10) will be determined by the nature of decision problems. For example, to choose the best machine based on its performance, the maximum utility should be considered. On the other hand, to invest in a new business based on minimum risk, the minimum utility will be considered.

\section{NUMERICAL EXPERIMENTS}

\section{A. Decision Making Under Uncertainty}

\section{1) Problem Illustration}

A numerical study is provided in this section to explain the practical implementation of the FEA under uncertainty. This experiment is conducted on Daffodil International University, Dhaka, Bangladesh to choose the best teacher by analyzing the Key Performance Indicators (KPI) set by the university authorities. The considered teachers for this experiment can be defined as $T_{1}, T_{2}, T_{3}$ and $T_{4}$. The input variables considered for obtaining the best teachers are defined as follows:

- $X_{1}$ : Delivery of course outline with an adequate number of text and reference books.

- $X_{2}$ : Seriousness about class time.

- $X_{3}$ : Delivery of practical examples in the class.

- $X_{4}$ : Lecture quality in terms of making the class topic clear and specific to the students.

- $X_{5}$ : Response to the students' questions in the classroom.
- $X_{6}$ : Consciousness about the arrangement and evaluation of required quizzes, assignments.

- $X_{7}$ : Coverage of course materials as per course outline.

- $X_{8}$ : Students' feedback.

- $X_{9}$ : Attendance in exam duty.

- $X_{10}$ : Punctuality about result submission time.

- $X_{11}$ : Activity in Learning Management System (LMS) and course repository.

- $X_{12}$ : Mentoring and counseling.

- $X_{13}$ : Research and publications.

- $X_{14}$ : Interpersonal relationships with the other teachers and working teams.

- $X_{15}$ : ResearchGate profile.

- $X_{16}$ : Attendance on conferences, seminars, and workshops.

- $X_{17}$ : Engagement in extracurricular activities.

The attribute weights considered for this experiment are: $W_{l}=0.5, W_{2}=0.7, W_{3}=0.8, W_{4}=1.0, W_{5}=0.7, W_{6}=0.7, W_{7}=0.9$, $W_{8}=0.8, \quad W_{9}=0.7, \quad W_{10}=0.7, \quad W_{11}=0.7, \quad W_{12}=0.85, \quad W_{13}=0.9$, $W_{14}=0.65, W_{15}=0.5, W_{16}=0.5, W_{17}=0.5$. In this example, 17 variables are used to determine the best teacher, where $X_{7}$ and $X_{9}$ are quantitative, $X_{15}$ is Boolean and the rest are qualitative. The inputs for the qualitative attributes are normalized to make the calculation easy and universal. The subjective evaluation of qualitative attributes is determined in Table II. The inputs collected against each alternative can be expressed using the attribute expression matrix. In Table III, the provided input $\left(E_{14}, 1.0\right)$ for $a_{11}$ describes that the input provider is $100 \%$ sure that the Delivery of Practical Examples in the class is $E_{14}$.

TABLE II. TRANSFORMATION OF EVALUATION GRADES INTO NUMERICAL VALUES

\begin{tabular}{|c|c|c|c|c|c|c|c|c|c|c|c|c|c|c|c|c|c|c|c|}
\hline$E_{1}$ & $E_{2}$ & $E_{3}$ & $E_{4}$ & $E_{5}$ & $E_{6}$ & $E_{7}$ & $E_{8}$ & $E_{9}$ & $E_{10}$ & $E_{11}$ & $E_{12}$ & $E_{13}$ & $E_{14}$ & $E_{15}$ & $E_{16}$ & $E_{17}$ & $E_{18}$ & $E_{19}$ & $E_{20}$ \\
\hline 0.05 & 0.1 & 0.15 & 0.2 & 0.25 & 0.3 & 0.35 & 0.4 & 0.45 & 0.5 & 0.55 & 0.6 & 0.65 & 0.7 & 0.75 & 0.8 & 0.85 & 0.9 & 0.95 & 1.0 \\
\hline
\end{tabular}

TABLE III. SYSTEM INPUT ACQUISITION

\begin{tabular}{|c|c|c|c|c|c|c|c|c|c|c|c|c|c|c|c|c|c|}
\hline & $X_{1}$ & $X_{2}$ & $X_{3}$ & $X_{4}$ & $X_{5}$ & $X_{6}$ & $X_{7}$ & $X_{8}$ & $X_{9}$ & $X_{10}$ & $X_{11}$ & $X_{12}$ & $X_{13}$ & $X_{14}$ & $X_{15}$ & $X_{16}$ & $X_{17}$ \\
\hline $\mathbf{T}_{1}$ & $E_{14}, 1.0$ & $E_{14}, 1.0$ & $E_{16}, 1.0$ & $E_{14}, 1.0$ & $E_{14}, 1.0$ & $E_{10}, 1.0$ & 0.9 & $E_{8}, 1.0$ & 0.9 & $E_{18}, 1.0$ & $E_{14}, 1.0$ & $E_{12}, 1.0$ & $E_{14}, 1.0$ & $E_{16}, 1.0$ & Yes & $E_{16}, 1.0$ & $E_{16,1.0}$ \\
\hline$T_{2}$ & $E_{14}, 1.0$ & $E_{16}, 1.0$ & $E_{14,}, 0.9$ & $E_{16,1.0}$ & $E_{16}, 1.0$ & $E_{16} 0.6$ & 0.9 & $E_{12}, 1.0$ & 0.7 & $E_{14,1.0}$ & $E_{14}, 1.0$ & $E_{14,1.0}$ & $E_{16}, 1.0$ & $E_{14,1.0}$ & No & $E_{12}, 1.0$ & $E_{12}, 1.0$ \\
\hline $\mathbf{T}_{3}$ & $E_{10}, 1.0$ & $E_{12}, 1.0$ & $E_{10}, 1.0$ & $E_{14,1.0}$ & $E_{13}, 1.0$ & $E_{12}, 1.0$ & 0.8 & $E_{10}, 1.0$ & 0.5 & $E_{6}, 1.0$ & $E_{12}, 1.0$ & $E_{12}, 1.0$ & $E_{10}, 1.0$ & $E_{12}, 1.0$ & Yes & $E_{10}, 1.0$ & $E_{8}, 1.0$ \\
\hline$T_{4}$ & $E_{14}, 1.0$ & $E_{14,1.0}$ & $E_{16,1.0}$ & $E_{14,0.8}$ & $E_{14}, 1.0$ & $E_{16,1.0}$ & 0.9 & $E_{10,}, 0.6$ & 0.9 & $E_{17}, 1.0$ & $E_{16}, 1.0$ & $E_{16,1.0}$ & $E_{4,1.0}$ & $E_{14,1.0}$ & No & $E_{15}, 1.0$ & $E_{12}, 1.0$ \\
\hline
\end{tabular}

In other cases, the user provides $80 \%$ and $90 \%$ confidence about the input value for $a_{23}\left(E_{14}, 0.8\right)$ and $a_{44}\left(E_{14}, 0.9\right)$. Here $20 \%$ and $10 \%$ of the information remains uncertain.

\section{2) Knowledgebase construction}

The basic knowledge base for this experiment is constructed with the help of 10 prominent university faculties and 7 experienced members of University trusty board as illustrated in Table IV.

\section{3) Step by Step Illustration of Utility Assessment with FEA}

a) Data Processing
- Transformation of complete information into quantitative format: To assess the performances of a teacher, first the inputs with complete information are transformed into numerical values according to the evaluation grades stated in Table II. The incomplete data are kept untransformed in this stage.

- Handling incomplete data: The proposed methodology suggests a way to capture the incomplete information provided by the user. The incomplete belief degrees are handled with the help of a belief rule-based knowledge base, e.g. in Table III, the input for attribute $a_{23}$ is $\left(E_{14}, 0.9\right)$ 
where 0.1 is ignorance. This ignorance can be handled with the help of the system's knowledge base (described in Table IV). In that case, the final input for $a_{23}$ will be:

$$
\begin{aligned}
& \left(E_{13} * 0.1\right)+\left(E_{14} * 0.85\right)+\left(E_{15} * 0.05\right)= \\
& (0.65 * 0.1)+(0.7 * 0.85)+(0.75 * 0.05)=0.697
\end{aligned}
$$

- Transformation of complete information into quantitative format: After the incomplete information is properly handled, the inputs are finally transformed to numeric values. Table VI shows the final input transformation.

\section{b) Inference Using Feature Extraction Approach}

After successfully transforming attributes' inputs into numeric values, the minimum value for every particular attribute of every alternative needs to be calculated. Attributes floor value for the given alternative can be calculated using (6) and the result is shown in Table VII. After obtaining the floor values, features are extracted for each attribute by (7). Finally, the probability mass for every attribute is measured by (8). The aggregated probability mass of all the attributes of an alternative provides its utility. To choose the best teacher, the maximum utility is considered in this that states the best performance (Figure 2).

TABLE IV. RULES SET UP FOR KNOWLEDGEBASE CONSTRUCTION

\begin{tabular}{|c|c|c|}
\hline Rule No. & Antecedent & Consequence \\
\hline $\mathbf{1 .}$ & if $\left(E_{1}, 0.8\right) \wedge\left(E_{2}, 0.1\right)$ & then $\left(E_{1}, 0.7\right),\left(E_{2}, 0.1\right),\left(E_{3}, 0.2\right)$ \\
\hline $\mathbf{2 .}$ & if $\left(E_{14}, 0.8\right)$ & then $\left(E_{13}, 0.2\right),\left(E_{14}, 0.7\right),\left(E_{15}, 0.1\right)$ \\
\hline $\mathbf{3}$ & if $\left(E_{16}, 0.6\right)$ & then $\left(E_{15}, 0.25\right),\left(E_{16}, 0.5\right),\left(E_{17}, 0.25\right)$ \\
\hline $\mathbf{4 .}$ & if $\left(E_{1}, 0.4\right) \wedge\left(E_{2}, 0.2\right) \wedge\left(E_{3}, 0.1\right)$ & then $\left(E_{1}, 0.3, E_{2}, 0.2, E_{3}, 0.1, E_{4}, 0.2, E_{5}, 0.2\right)$ \\
\hline $\mathbf{5 .}$ & if $\left(E_{3}, 0.4\right) \wedge\left(E_{4}, 0.4\right)$ & then $\left(E_{3}, 0.3, E_{4}, 0.3, E_{5}, 0.3, E_{5}, 0.1\right)$ \\
\hline $\mathbf{6 .}$ & if $\left(E_{3}, 0.2\right) \wedge\left(E_{4}, 0.5\right) \wedge\left(E_{5}, 0.2\right)$ & then $\left(E_{3}, 0.15, E_{4}, 0.4, E_{5}, 0.25, E_{5}, 0.2\right)$ \\
\hline $\mathbf{7 .}$ & if $\left(E_{5}, 0.3\right) \wedge\left(E_{6}, 0.3\right) \wedge\left(E_{7}, 0.2\right)$ & then $\left(E_{5}, 0.25, E_{6}, 0.2, E_{7}, 0.2, E_{8}, 0.2, E_{9}, 0.15\right)$ \\
\hline $\mathbf{8 .}$ & if $\left(E_{5}, 0.6\right) \wedge\left(E_{6}, 0.3\right)$ & then $\left(E_{5}, 0.4, E_{6}, 0.2, E_{7}, 0.2, E_{8}, 0.2\right)$ \\
\hline $\mathbf{9 .}$ & if $\left(E_{6}, 0.5\right) \wedge\left(E_{7}, 0.3\right)$ & then $\left(E_{6}, 0.4, E_{7}, 0.25, E_{8}, 0.25, E_{9}, 0.1\right)$ \\
\hline $\mathbf{1 0 .}$ & if $\left(E_{14}, 0.9\right)$ & then $\left(E_{13}, 0.1\right),\left(E_{14}, 0.85\right),\left(E_{15}, 0.05\right)$ \\
\hline $\mathbf{1 1}$ & If $\left(E_{7}, 0.5\right) \wedge\left(E_{8}, 0.3\right)$ & then $\left(E_{7}, 0.4, E_{8}, 0.25, E_{9}, 0.25, E_{10}, 0.1\right)$ \\
\hline $\mathbf{1 2}$ & if $\left(E_{8}, 0.4\right) \wedge\left(E_{9}, 0.4\right)$ & then $\left(E_{7}, 0.3, E_{8}, 0.3, E_{9}, 0.3, E_{10}, 0.1\right)$ \\
\hline $\mathbf{1 3}$ & if $\left(E_{10}, 0.2\right) \wedge\left(E_{11}, 0.7\right)$ & $\operatorname{then}\left(E_{10}, 0.2, E_{11}, 0.6, E_{12}, 0.2\right)$ \\
\hline $\mathbf{1 4}$ & if $\left(E_{10}, 0.4\right) \wedge\left(E_{11}, 0.3\right) \wedge\left(E_{12}, 0.1\right)$ & then $\left(E_{10}, 0.25, E_{11}, 0.25, E_{12}, 0.25, E_{13}, 0.25\right)$ \\
\hline $\mathbf{1 5}$ & if $\left(E_{11}, 0.4\right) \wedge\left(E_{12}, 0.3\right)$ & then $\left(E_{11}, 0.35, E_{12}, 0.25, E_{13}, 0.25, E_{14}, 0.15\right)$ \\
\hline $\mathbf{1 6}$ & if $\left(E_{13}, 0.3\right) \wedge\left(E_{14}, 0.4\right)$ & then $\left(E_{13}, 0.35, E_{14}, 0.3, E_{15}, 0.35\right)$ \\
\hline $\mathbf{1 7}$ & if $\left(E_{15}, 0.3\right) \wedge\left(E_{16}, 0.2\right)$ & then $\left(E_{15}, 0.35, E_{16}, 0.25, E_{15}, 0.25, E_{16}, 0.15\right)$ \\
\hline $\mathbf{1 8}$ & if $\left(E_{17}, 0.3\right) \wedge\left(E_{16}, 0.3\right)$ & then $\left(E_{17}, 0.35, E_{16}, 0.35, E_{15}, 0.25, E_{14}, 0.1\right)$ \\
\hline
\end{tabular}

TABLE V. INITIAL INPUT TRANSFORMATION WITH INCOMPLETE INFORMATION

\begin{tabular}{|c|c|c|c|c|c|c|c|c|c|c|c|c|c|c|c|c|c|}
\hline & $\boldsymbol{X}_{1}$ & $\boldsymbol{X}_{\mathbf{2}}$ & $\boldsymbol{X}_{\mathbf{3}}$ & $\boldsymbol{X}_{4}$ & $\boldsymbol{X}_{5}$ & $\boldsymbol{X}_{\mathbf{6}}$ & $\boldsymbol{X}_{7}$ & $\boldsymbol{X}_{8}$ & $\boldsymbol{X}_{\boldsymbol{9}}$ & $\boldsymbol{X}_{10}$ & $\boldsymbol{X}_{11}$ & $\boldsymbol{X}_{12}$ & $\boldsymbol{X}_{13}$ & $\boldsymbol{X}_{14}$ & $\boldsymbol{X}_{15}$ & $\boldsymbol{X}_{16}$ & $\boldsymbol{X}_{17}$ \\
\hline $\mathbf{T}_{\mathbf{1}}$ & 0.7 & 0.7 & 0.8 & 0.7 & 0.7 & 0.5 & 0.9 & 0.4 & 0.9 & 0.9 & 0.7 & 0.6 & 0.7 & 0.8 & 1 & 0.8 & 0.8 \\
\hline $\mathbf{T}_{\mathbf{2}}$ & 0.7 & 0.8 & $E_{14}, 0.9$ & 0.8 & 0.8 & $E_{16}, 0.6$ & 0.9 & 0.6 & 0.7 & 0.7 & 0.7 & 0.7 & 0.8 & 0.7 & 0 & 0.6 & 0.6 \\
\hline $\mathbf{T}_{3}$ & 0.5 & 0.6 & 0.5 & 0.7 & 0.65 & 0.6 & 0.8 & 0.5 & 0.5 & 0.3 & 0.6 & 0.6 & 0.5 & 0.6 & 1 & 0.5 & 0.4 \\
\hline $\mathbf{T}_{\mathbf{4}}$ & 0.7 & 0.7 & 0.8 & $E_{14}, 0.8$ & 0.7 & 0.8 & 0.9 & 0.5 & 0.9 & 0.85 & 0.8 & 0.8 & 0.2 & 0.7 & 0 & 0.75 & 0.6 \\
\hline
\end{tabular}

TABLE VI. FINAL INPUT TRANSFORMATION

\begin{tabular}{|c|c|c|c|c|c|c|c|c|c|c|c|c|c|c|c|c|c|}
\hline & $\boldsymbol{X}_{1}$ & $\boldsymbol{X}_{\mathbf{2}}$ & $\boldsymbol{X}_{3}$ & $\boldsymbol{X}_{4}$ & $\boldsymbol{X}_{5}$ & $\boldsymbol{X}_{\mathbf{6}}$ & $\boldsymbol{X}_{7}$ & $\boldsymbol{X}_{\boldsymbol{8}}$ & $\boldsymbol{X}_{\mathbf{9}}$ & $\boldsymbol{X}_{10}$ & $\boldsymbol{X}_{11}$ & $\boldsymbol{X}_{12}$ & $\boldsymbol{X}_{13}$ & $\boldsymbol{X}_{14}$ & $\boldsymbol{X}_{15}$ & $\boldsymbol{X}_{16}$ & $\boldsymbol{X}_{17}$ \\
\hline $\mathbf{T}_{\mathbf{1}}$ & 0.7 & 0.7 & 0.8 & 0.7 & 0.7 & 0.5 & 0.9 & 0.4 & 0.9 & 0.9 & 0.7 & 0.6 & 0.7 & 0.8 & 1 & 0.8 & 0.8 \\
\hline $\mathbf{T}_{\mathbf{2}}$ & 0.7 & 0.8 & 0.697 & 0.8 & 0.8 & 0.8 & 0.9 & 0.6 & 0.7 & 0.7 & 0.7 & 0.7 & 0.8 & 0.7 & 0 & 0.6 & 0.6 \\
\hline $\mathbf{T}_{\mathbf{3}}$ & 0.5 & 0.6 & 0.5 & 0.7 & 0.65 & 0.6 & 0.8 & 0.5 & 0.5 & 0.3 & 0.6 & 0.6 & 0.5 & 0.6 & 1 & 0.5 & 0.4 \\
\hline $\mathbf{T}_{\mathbf{4}}$ & 0.7 & 0.7 & 0.8 & 0.695 & 0.7 & 0.8 & 0.9 & 0.5 & 0.9 & 0.85 & 0.8 & 0.8 & 0.2 & 0.7 & 0 & 0.75 & 0.6 \\
\hline
\end{tabular}

TABLE VII. ATTRIBUTES’ MINIMUM VALUE CALCULATION

\begin{tabular}{|c|c|c|c|c|c|c|c|c|c|c|c|c|c|c|c|c|c|}
\hline & $\boldsymbol{X}_{1}$ & $\boldsymbol{X}_{2}$ & $\boldsymbol{X}_{3}$ & $\boldsymbol{X}_{4}$ & $\boldsymbol{X}_{5}$ & $\boldsymbol{X}_{\mathbf{6}}$ & $\boldsymbol{X}_{7}$ & $\boldsymbol{X}_{8}$ & $\boldsymbol{X}_{9}$ & $\boldsymbol{X}_{10}$ & $\boldsymbol{X}_{11}$ & $\boldsymbol{X}_{12}$ & $\boldsymbol{X}_{13}$ & $\boldsymbol{X}_{14}$ & $\boldsymbol{X}_{15}$ & $\boldsymbol{X}_{16}$ & $\boldsymbol{X}_{17}$ \\
\hline $\mathbf{T}_{1}$ & 0.7 & 0.7 & 0.8 & 0.7 & 0.7 & 0.5 & 0.9 & 0.4 & 0.9 & 0.9 & 0.7 & 0.6 & 0.7 & 0.8 & 1 & 0.8 & 0.8 \\
\hline $\mathbf{T}_{\mathbf{2}}$ & 0.7 & 0.8 & 0.697 & 0.8 & 0.8 & 0.8 & 0.9 & 0.6 & 0.7 & 0.7 & 0.7 & 0.7 & 0.8 & 0.7 & 0 & 0.6 & 0.6 \\
\hline $\mathbf{T}_{3}$ & 0.5 & 0.6 & 0.5 & 0.7 & 0.65 & 0.6 & 0.8 & 0.5 & 0.5 & 0.3 & 0.6 & 0.6 & 0.5 & 0.6 & 1 & 0.5 & 0.4 \\
\hline $\mathbf{T}_{\mathbf{4}}$ & 0.7 & 0.7 & 0.8 & 0.695 & 0.7 & 0.8 & 0.9 & 0.5 & 0.9 & 0.85 & 0.8 & 0.8 & 0.2 & 0.7 & 0 & 0.75 & 0.6 \\
\hline $\mathbf{M i n}$ & 0.5 & 0.6 & 0.5 & 0.695 & 0.65 & 0.5 & 0.8 & 0.4 & 0.5 & 0.3 & 0.6 & 0.6 & 0.2 & 0.6 & 0 & 0.5 & 0.4 \\
\hline
\end{tabular}

TABLE VIII. ATTRIBUTES’ FEATURE EXTRACTION

\begin{tabular}{|c|c|c|c|c|c|c|c|c|c|c|c|c|c|c|c|c|c|}
\hline & $\boldsymbol{X}_{1}$ & $\boldsymbol{X}_{\mathbf{2}}$ & $\boldsymbol{X}_{\mathbf{3}}$ & $\boldsymbol{X}_{4}$ & $\boldsymbol{X}_{5}$ & $\boldsymbol{X}_{\mathbf{6}}$ & $\boldsymbol{X}_{7}$ & $\boldsymbol{X}_{\boldsymbol{8}}$ & $\boldsymbol{X}_{\mathbf{9}}$ & $\boldsymbol{X}_{10}$ & $\boldsymbol{X}_{11}$ & $\boldsymbol{X}_{12}$ & $\boldsymbol{X}_{13}$ & $\boldsymbol{X}_{14}$ & $\boldsymbol{X}_{15}$ & $\boldsymbol{X}_{16}$ & $\boldsymbol{X}_{17}$ \\
\hline $\mathbf{T}_{\mathbf{1}}$ & 0.2 & 0.1 & 0.3 & 0.005 & 0.05 & 0 & 0.1 & 0 & 0.4 & 0.6 & 0.1 & 0 & 0.5 & 0.2 & 1 & 0.3 & 0.4 \\
\hline $\mathbf{T}_{\mathbf{2}}$ & 0.2 & 0.2 & 0.197 & 0.105 & 0.15 & 0.3 & 0.1 & 0.2 & 0.2 & 0.4 & 0.1 & 0.1 & 0.6 & 0.1 & 0 & 0.1 & 0.2 \\
\hline $\mathbf{T}_{\mathbf{3}}$ & 0 & 0 & 0 & 0.005 & 0 & 0.1 & 0 & 0.1 & 0 & 0 & 0 & 0 & 0.3 & 0 & 1 & 0 & 0 \\
\hline $\mathbf{T}_{\mathbf{4}}$ & 0.2 & 0.1 & 0.3 & 0 & 0.05 & 0.3 & 0.1 & 0.1 & 0.4 & 0.55 & 0.2 & 0.2 & 0 & 0.1 & 0 & 0.25 & 0.2 \\
\hline
\end{tabular}


TABLE IX. ALTERNATIVES' UTILITY CALCULATION

\begin{tabular}{|c|c|c|c|c|c|c|c|c|c|c|c|c|c|c|c|c|c|c|}
\hline & $X_{1}$ & $X_{2}$ & $X_{3}$ & $X_{4}$ & $X_{5}$ & $X_{6}$ & $X_{7}$ & $X_{8}$ & $X_{9}$ & $X_{10}$ & $X_{11}$ & $X_{12}$ & $X_{13}$ & $X_{14}$ & $X_{15}$ & $X_{16}$ & $X_{17}$ & Utility \\
\hline$T_{1}$ & 0.1 & 0.07 & 024 & 005 & 025 & 0 & & 0 & & 0.42 & 007 & 0 & 0.45 & 0.13 & 0.5 & 0.15 & 0.2 & 2.74 \\
\hline $\mathbf{T}_{2}$ & 0.1 & .14 & 91 & $J$ & .105 & 0.3 & 19 & .16 & 0.14 & 0.28 & 0.07 & .085 & 54 & .06 & 0 & 0.05 & 0.1 & 32 \\
\hline $\mathbf{T}_{3}$ & 0 & 0 & & 005 & 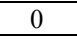 & O & 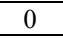 & & 0 & 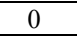 & & & 0.27 & & 0.5 & & 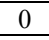 & 0.925 \\
\hline $\mathbf{T}_{4}$ & 0.1 & 07 & .24 & 0 & .035 & .21 & 0.09 & 0.08 & .28 & .385 & 0.14 & 0.17 & 0 & 0.065 & 0 & 0.125 & 0.1 & 2.09 \\
\hline
\end{tabular}

From the graph in Figure 2, it becomes clear that $T_{1}$ performs better than the rest and so, $\mathrm{T}_{1}$ is selected as the best teacher. To visualize the accuracy of the proposed methodology, a comparative evaluation between the systemobtained results and established benchmark results is presented in Table $\mathrm{X}$ and its graphical representation is shown in Figure 3. The benchmark results are collected from the Human Resource (HR) department at Daffodil International University (DIU).

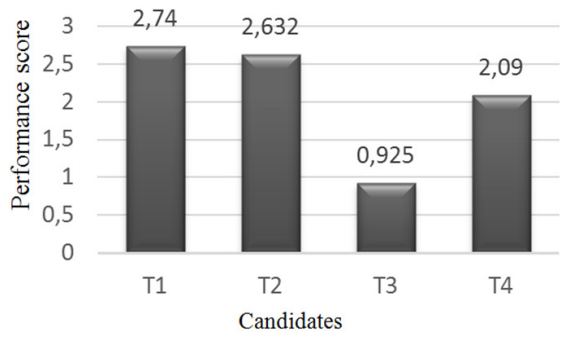

Fig. 2. Teachers' performance evaluation

TABLE X. CROSS-VALIDATION BETWEEN EXPERIMENTAL AND BENCHMARK RESULTS

\begin{tabular}{|c|c|c|c|c|}
\hline Location & $\begin{array}{c}\text { System obtained } \\
\text { results }\end{array}$ & $\begin{array}{c}\text { Benchmark } \\
\text { results }\end{array}$ & $\begin{array}{c}\text { System } \\
\text { inference }\end{array}$ & $\begin{array}{c}\text { HR at DIU } \\
\text { inference }\end{array}$ \\
\hline $\mathbf{T}_{\mathbf{1}}$ & 2.74 & 2.71 & & \\
\hline $\mathbf{T}_{\mathbf{2}}$ & 2.632 & 2.5 & \multirow{2}{*}{$\mathrm{T}_{1}$} & $\mathrm{~T}_{1}$ \\
\hline $\mathbf{T}_{\mathbf{3}}$ & 0.925 & 0.98 & & \\
\hline $\mathbf{T}_{\mathbf{4}}$ & 2.09 & 1.96 & & \\
\hline
\end{tabular}

- System Obtained Results $\quad$ Benchmark Results

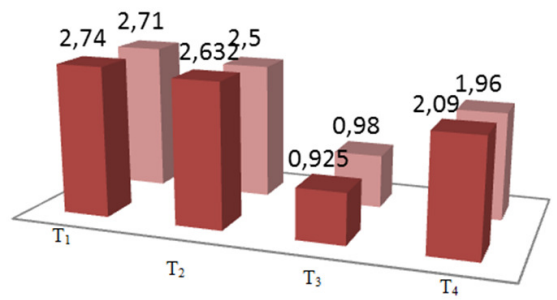

Fig. 3. Graphical representation of cross-validation between the experimental results and the benchmark results

\section{B. Decision Making Under Risk}

\section{1) Problem Illustration}

This numerical study is presented to explain the practical implementation of FEA under risk. This experiment is conducted to select the best location to rent a house from a course of alternatives based on four basic attributes. The input variables for this experiment have been determined by analyzing 10 years of historical data collected from GIS (Geographic Information System) and RAJUK (Rajdhani
Unnayan Kartripakkha).The probabilities of attributes are determined by analysing 10 years' historical data. The locations considered for this experiment are defined as: $\mathrm{L}_{1}=$ Location $\mathrm{A}, \mathrm{L}_{2}=$ Location $\mathrm{B}, \mathrm{L}_{3}=$ Location $\mathrm{C}$, and $\mathrm{L}_{4}=$ Location D.

The input variables or the attributes considered for choosing the best location to rent a house can be defined as:

- $X_{1}$ : Probability of the area getting flooded during the rainy season.

- $X_{2}$ : Probability of load shedding occurrence in the area.

- $X_{3}$ : Probability of gas crisis occurrence in the area.

- $X_{4}$ : Probability of water crisis occurrence in the area.

The input values for these four attributes have been determined as shown in Table XI:

TABLE XI. ATTRIBUTES' DEGREE OF PROBABILITY

\begin{tabular}{|l|l|l|l|l|}
\hline & $\boldsymbol{X}_{1}$ & $\boldsymbol{X}_{\mathbf{2}}$ & $\boldsymbol{X}_{3}$ & $\boldsymbol{X}_{4}$ \\
\hline $\mathbf{L}_{\mathbf{1}}$ & 0.2 & 0.3 & 0.5 & 0.5 \\
\hline $\mathbf{L}_{\mathbf{2}}$ & 0.5 & 0.4 & 0.4 & 0.6 \\
\hline $\mathbf{L}_{3}$ & 0.3 & 0.2 & 0.7 & 0.2 \\
\hline $\mathbf{L}_{\mathbf{4}}$ & 0.7 & 0.3 & 0.3 & 0.6 \\
\hline
\end{tabular}

The attribute weights, collected from the domain experts, considered for this experiment are $W_{1}=0.5, W_{2}=0.85, W_{3}=0.9$, and $W_{4}=0.95$.

\section{2) Selecting an Optimal Location with FEA}

To choose the best location to rent a house, the feature of every single attribute is extracted through a cross judgment of attributes against all the alternatives. To extract the feature of an attribute, at first the minimum value for every attribute is calculated as shown in Table XII.

TABLE XII. ATTRIBUTES' FLOOR VALUE CALCULATION

\begin{tabular}{|c|c|c|c|c|}
\hline & $\boldsymbol{X}_{1}$ & $\boldsymbol{X}_{2}$ & $\boldsymbol{X}_{3}$ & $\boldsymbol{X}_{4}$ \\
\hline $\mathbf{L}_{1}$ & 0.2 & 0.3 & 0.5 & 0.5 \\
\hline $\mathbf{L}_{2}$ & 0.5 & 0.4 & 0.4 & 0.6 \\
\hline $\mathbf{L}_{3}$ & 0.3 & 0.2 & 0.7 & 0.2 \\
\hline $\mathbf{L}_{4}$ & 0.7 & 0.3 & 0.3 & 0.6 \\
\hline Min & 0.2 & 0.2 & 0.3 & 0.2 \\
\hline
\end{tabular}

Then, the feature of every attribute is extracted with the help of (7), as shown in Table XIII.

TABLE XIII. ATTRIBUTES' FEATURE DETERMINATION

\begin{tabular}{|c|c|c|c|c|}
\hline & $\boldsymbol{X}_{\boldsymbol{I}}$ & $\boldsymbol{X}_{\mathbf{2}}$ & $\boldsymbol{X}_{\mathbf{3}}$ & $\boldsymbol{X}_{\mathbf{4}}$ \\
\hline $\mathbf{L}_{\mathbf{1}}$ & 0 & 0.1 & 0.2 & 0.3 \\
\hline $\mathbf{L}_{\mathbf{2}}$ & 0.3 & 0.2 & 0.1 & 0.4 \\
\hline $\mathbf{L}_{3}$ & 0.1 & 0 & 0.4 & 0 \\
\hline $\mathbf{L}_{\mathbf{4}}$ & 0.5 & 0.1 & 0 & 0.4 \\
\hline
\end{tabular}


Finally, the probability mass for every attribute is measured by (8). The aggregated probability mass of all the attributes of an alternative provides its risk severity.

TABLE XIV. ATTRIBUTES' RISK-SEVERITY CALCULATION

\begin{tabular}{|c|c|c|c|c|c|}
\hline & $\boldsymbol{X}_{\boldsymbol{1}}$ & $\boldsymbol{X}_{\mathbf{2}}$ & $\boldsymbol{X}_{\mathbf{3}}$ & $\boldsymbol{X}_{\mathbf{4}}$ & Risk severity \\
\hline $\mathbf{L}_{\mathbf{1}}$ & 0 & 0.085 & 0.18 & 0.285 & 0.55 \\
\hline $\mathbf{L}_{\mathbf{2}}$ & 0.15 & 0.17 & 0.09 & 0.38 & 0.79 \\
\hline $\mathbf{L}_{\mathbf{3}}$ & 0.05 & 0 & 0.36 & 0 & 0.41 \\
\hline $\mathbf{L}_{\mathbf{4}}$ & 0.25 & 0.085 & 0 & 0.38 & 0.715 \\
\hline
\end{tabular}

To choose the best location in order to rent a house, the location with minimum score is considered in this experiment, as the minimum risk score ensures the maximum privilege (Figure 4). From Figure 4, it becomes clear that Location C states lesser risk than all the rest alternatives and so, Location $\mathrm{C}$ is selected as the best location to rent a house. To validate that the experimental results reflect the most accurate consequences, cross-validation between the experimental results and the benchmark results is exhibited in Table XV and Figure 5.

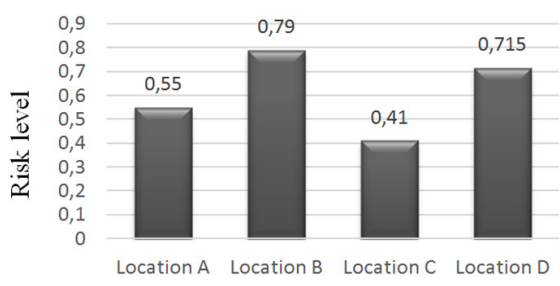

Fig. 4. Risk severity assessment

TABLE XV. CROSS EVALUATION OF EXPERIMENTAL AND BENCHMARK RESULTS

\begin{tabular}{|c|c|c|c|c|}
\hline Location & $\begin{array}{c}\text { System obtained } \\
\text { results }\end{array}$ & $\begin{array}{c}\text { Benchmark } \\
\text { results }\end{array}$ & $\begin{array}{c}\text { System } \\
\text { inference }\end{array}$ & $\begin{array}{c}\text { RAJUK } \\
\text { inference }\end{array}$ \\
\cline { 1 - 3 } $\mathbf{L}_{\mathbf{1}}$ & $0.55(55 \%)$ & $0.5(50 \%)$ & & \\
\cline { 1 - 3 } $\mathbf{L}_{\mathbf{2}}$ & $0.74(74 \%)$ & $0.8(80 \%)$ & \multirow{2}{*}{$\mathrm{L}_{3}$} & \multirow{2}{*}{$\mathrm{L}_{3}$} \\
\cline { 1 - 3 } $\mathbf{L}_{3}$ & $0.41(41 \%)$ & $0.45(45 \%)$ & & \\
\cline { 1 - 3 } $\mathbf{L}_{4}$ & $0.715(71.5 \%)$ & $0.75(75 \%)$ & & \\
\hline
\end{tabular}

- System Obtained Results Benchmark Results 0,8

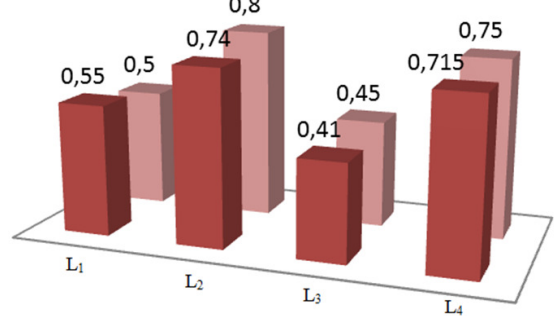

Fig. 5. Graphical representation of cross-validation

\section{CONCLUSION}

Decision-makers may need to analyze various types of information to achieve the optimal solution for a decision problem. Decision problems often come with multiple attributes and an individual may need to make decisions under risk and uncertainty. So, the decision-making approach must be optimized enough to conclude any type of decision problems into a rational, reliable, and transparent solution. The feature extraction approach proposed in this paper is competent enough to make decisions under risk and uncertainty. The system provides a rational means to capture qualitative and quantitative attributes along with Boolean data to make a dynamic decision-making approach. For decision making under uncertainty, the proposed system extracts features from the inputs provided by the decision makers. So, decision making under uncertainty is normally triggered with providing some input variables and its associated weights against all the decision attributes to deduce the best solution. In the case of decision making under risk, decision-makers need to provide the probabilities of the attributes in terms of real event occurrences that impact the decision solutions. For that purpose, some previous data on those respective attributes need to be analyzed to measure each of its degree of probability.

The numerical experiments presented in this paper provide the practical implementation of the feature extraction approach for deducing optimal solutions for decision-making problems under uncertainty and risk. In both experiments, relative attribute weights have been collected from domain experts. These experiments clearly state that the feature extraction approach can capture multiple attributes for providing the optimal solutions for decision problems under risk and uncertainty.

\section{REFERENCES}

[1] V. Belton, T. J. Stewart, Multiple criteria decision analysis: An integrated approach, Kluwer Academic, 2002

[2] C. L. Huang, K. Yoon, Multiple attribute decision making: Methods and applications: A state-of-art survey, Springer, 1981

[3] B. Roy, D. Vanderpooten, "The European school of MCDA: Emergence, basic features and current works", Journal of Multi-Criteria Decision Analysis, Vol. 5, No. 1, pp. 22-38, 1996

[4] T. L. Saaty, The analytic hierarchy process, McGraw-Hill, 1980

[5] T. J. Stewart, "A critical survey on the status of multiple criteria decision making theory and practice", Omega, Vol. 20, No. 5-6, pp. 569-586, 1992

[6] J. B. Yang, M. G. Singh, “An evidential reasoning approach for multiple-attribute decision making with uncertainty", IEEE Transactions on Systems, Man, and Cybernetics, Vol. 24, No. 1, pp. 1-18, 1994

[7] N. Benmoussa, A. Elyamami, K. Mansouri, M. Qbadou, E. Illoussamen, "A multi-criteria decision making approach for enhancing university accreditation process", Engineering, Technology \& Applied Science Research, Vol. 9, No. 1, pp. 3726-3733, 2019

[8] B. Trstenjak, B. Palasek, J. Trstenjak, "A decision support system for the prediction of wastewater pumping station failures based on CBR continuous learning model", Engineering, Technology \& Applied Science Research, Vol. 9, No. 5, pp. 4745-4749, 2019

[9] J. Wallenius, J. S. Dyer, P. C. Fishburn, R. E. Steuer, S. Zionts, K. Deb, "Multiple criteria decision making, multiattribute utility theory: Recent accomplishments and what lies ahead", Management Science, Vol. 54, No. 7, pp. 1336-1349, 2008

[10] W. Ho, X. Xu, P. K. Dey, "Multi-criteria decision making approaches for supplier evaluation and selection: A literature review", European Journal of Operational Research, Vol. 202, No. 1, pp. 16-24, 2010

[11] G. A. Miller, "The magical number seven, plus or minus two: Some limits on our capacity for processing information", Psychological Review, Vol. 63, No. 2, pp. 81-97, 1956

[12] L. Hurwicz, "The generalized bayes minimax principle: A criterion for decision making uncer ucertainty", Cowles Commition Discussion Paper: Statistics No 355, 1951 
[13] C. W. Churchman, R. L. Ackoff, "An approximate measure of value", Journal of the Operational Research Society of America, Vol. 2, No. 2, pp. 107-226, 1954

[14] T. L. Saaty, "The analytic hierarchy process: What it is and how it is used", Mathematical Modelling, Vol. 9, No. 3-5, pp. 161-176, 1987

[15] P. K. Dey, "Integrated project evaluation and selection using multipleattribute decision-making technique", International Journal of Production Economics, Vol. 103, No. 1, pp. 90-103, 2006

[16] H. Deng, C. H. Yeh, R. J. Willis, "Inter-company comparison using modified TOPSIS with objective weights", Computers and Operations Research, Vol. 27, No. 10, pp. 963-973, 2000

[17] M. Haddad, D. Sanders, "Selection of discrete multiple criteria decision making methods in the presence of risk and uncertainty", Operations Research Perspectives, Vol. 5, pp. 357-370, 2018

[18] A. Shanian, O. Savadogo, "TOPSIS multiple-criteria decision support analysis for material selection of metallic bipolar plates for polymer electrolyte fuel cell", Journal of Power Sources, Vol. 159, No. 2, pp. 1095-1104, 2006

[19] A. Kelemenis, D. Askounis, "A new TOPSIS-based multi-criteria approach to personnel selection", Expert Systems with Applications, Vol. 37, No. 7, pp. 4999-5008, 2010

[20] G. D. Li, D. Yamaguchi, M. Nagai, "A grey-based decision-making approach to the supplier selection problem", Mathematical \& Computer Modelling, Vol. 46, No. 3-4, pp. 573-581, 2007

[21] L. A. Zadeh, "Fuzzy sets", Information and Computation, Vol. 8, No. 3, pp. 338-353, 1965

[22] I. B. Turksen, "Interval valued fuzzy sets based on normal forms", Fuzzy Sets and Systems, Vol. 20, No. 2, pp. 191-210, 1986

[23] S. Miyamoto, "Fuzzy multisets and their generalizations", in: Workshop on Membrane Computing, Vol. 2235, Springer, 2000

[24] K. T. Atanassov, "Intuitionistic fuzzy sets", Fuzzy Sets and Systems, Vol. 20, No. 1, pp. 87-96, 1986

[25] Z. Xu, "Uncertain linguistic aggregation operators based approach to multiple attribute group decision making under uncertain linguistic environment", Information Sciences, Vol. 168, No. 1-4, pp. 171-184, 2004

[26] V. Torra, "Hesitant fuzzy sets", International Journal of Intelligent Systems, Vol. 25, No. 6, pp. 529-539, 2010

[27] R. L. De Mantaras, Approximate reasoning models, Ellis Horwood, 1990

[28] J. B. Yang, D. L. Xu, "On the evidential reasoning algorithm for multiple attribute decision analysis under uncertainty", IEEE Transactions on Systems, Man, and Cybernetics-Part A: Systems and Humans, Vol. 32, No. 3, pp. 289-304, 2002

[29] J. B. Yang, D. L. Xu, "Knowledge-based executive car evaluation using the evidential reasoning approach", in: Advances in Manufacturing Technology XII, Professional Engineering Publishing, 1998

[30] J. Wang, J. B. Yang, “A subjective safety and cost based decision model for assessing safety requirements specifications", International Journal of Reliability, Quality and Safety Engineering, Vol. 8, No. 1, pp. 35-57, 2001

[31] J. B. Yang, J. Liu, J. Wang, H. S. Sii, H. W. Wang, "Belief rule-base inference methodology using the evidential reasoning approachRIMER", IEEE Transactions on Systems, Man, and Cybernetics-Part A: Systems and Humans, Vol. 36, No. 2, pp. 266-285, 2006

[32] J. V. Neumann, O. Morgenstern, Theory of games and economic behavior, Princeton University Press, 2007

[33] M. Allais, "L'extension des theories de l'equilibre economique general et du rendement social au cas du risque", Journal of the Econometric Society, Vol. 21, No. 2, pp. 269-290, 1953 (in French)

[34] D. Kahneman, A. Tversky, "Prospect theory: An analysis of decision under risk", Journal of the Econometric Society, Vol. 47, No. 2, pp. $263-$ 291, 1979

[35] A. Tversky, D. Kahneman, "Advances in prospect theory: Cumulative representation of uncertainty", Journal of Risk and Uncertainty, Vol. 5, No. 4, pp. 297-323, 1992
[36] M. H. Birnbaum, "The nonadditivity of personality impressions", Journal of Experimental Psychology Monograph, Vol. 102, No. 3, pp. 543-561, 1974

[37] M. H. Birnbaum, A. Chavez, "Tests of theories of decision making: Violations of branch independence and distribution independence", Organizational Behavior and Human Decision Processes, Vol. 71, No. 2, pp. 161-194, 1997

[38] M. Hazewinkel, Minimax principle, Encyclopaedia of mathematics, Springer, 2001

[39] G. H. Tzeng, J. J. Huang, Multiple attribute decision making: Methods and applications, Chapman and Hall, 2011

[40] J. Barzilai, "Deriving weights from pairwise comparison matrices", Journal of the Operational Research Society, Vol. 48, No. 12, pp. 12261232, 1997 